\title{
Subjective Well-Being, Psychological Well-Being, and Islamic Religiosity
}

\author{
Faizah Binti Awad ${ }^{1}$, Ros Mayasari ${ }^{2}$ \\ ${ }^{1,2}$ STAIN Kendari, South-East Sulawesi, Indonesia
}

\begin{abstract}
Attention and study of the problem of happiness and prosperity in the field of psychology are specifically motivated by the positive psychology movement. Positive psychology is a new movement in the disciplines of psychology that emphasizes on the exploration of potentials in human beings. Well-being in the context of positive psychology evolved in two different approaches hedonic and eudemonic approaches - also referred to as SWB and psychological well-being. Research on the development of well-being has entered the discourse of whether the two approaches are of identical or distinct constructs. This study aims to investigate whether the SWB and psychological well-being are indistinguishable constructs, and to scrutinize the relationship between these two constructs with religiosity. Data were collected from questionnaires filled out by 159 students of IAIN Kendari. The results indicate that both constructs of well-being are completely different and are not even related. Of the two constructs of well-being, only psychological wellbeing has a significant correlation with religiosity.
\end{abstract}

Keywords: happiness, SWB (SWB), psychological well-being (PWB), religiosity

\section{Introduction}

Well-being in the context of positive psychology is the current topic of much research in developmental psychology. There are two approaches to understanding well-being. The first approach derives from the opinion of Bradburn (Awaningrum, 2007) who defines psychological well-being (herein after PWB) as happiness, which is the highest goal to be achieved by human beings and the balance between positive and negative affectivity. Such understanding of 'psychological welfare' as mentioned above is generally referred to as the subjective well-being (herein after SWB).

The second approach is the concept of well-being proposed by Ryff (1989). According to Ryff, PWB is related to not only freeing a person from the negative affectivity such as anxiety or depression, but also to an understanding of the positive potential in him and the personal growth. This concept of well-being is subsequently known as PWB.

The development of this 'well-being' research has reached the stage of critically questioning the relationship between these two concepts of well being (PWB and SWB). According to limited research (e.g. Keyes, Shmotkin and Ryff, 2002; Walker, 2009; Linley, Maltby, Wood, Osborne, Hurling, 2009) these two concepts are different, but are inter-related. These researchers recommended that both concepts be re-examined with extensive and larger research subjects across cultures and countries. This is necessary because existing research studies are typically conducted with subjects in countries referred to as WEIRD (Western, Educated, Industrialized, Rich, Democratic). Whether these two concepts are shared by people from different social contexts, backgrounds, and cultures, such as Indonesia, who are known as collectivistic and religious, remains an open question. In other words, it is important to examine whether the concept of 'well-being' is universal or whether it is subject to variations in the aforementioned social contexts.
Additionally, Ryff and Singer (1996) argue that religiosity is one factor affecting well- being. In fact, research studies, such as those of Tiliouine at.al (2009), Maulina (2011), Rinasti (2011) also suggest that religiosity is associated with well-being. However, a study conducted by Walker (2009) yielded conflicting results, in that religiosity has no association with well-being. These inconsistent findings necessitate the need for further investigation. In this case, a particular question worth asking includes, but is not limited to, whether SWB and PWB are taxonomically distinct, overlapping, or whether they belong to entirely different constructs. The second question pertains to the relationship between SWB, PWB, and religiosity and whether religiosity is more strongly related to one of the above concepts of well-being.

\section{Psychological Well-Being}

Carol D Ryff, the proponent of the theory of PWB, points out that the term PWB can be understood as full achievement of the psychological potential in a person and a situation where an individual can accept his/her strengths and weaknesses, has a purpose in life, develops positive relationships with others, becomes an independent person, is capable of mastery the environment (environmental mastery), and continues to grow personally (Ryff, 1989).

The characteristics of people who have PWB defined by Ryff (1989) are in line with the views of Rogers regarding fully-functioning person, the views of Maslow's concerning self actualization, Jung's view of individuation, Allport's concept of maturity, as well as Erikson's concept when describing individuals who achieve integration rather than despair. Furthermore, Ryff (1989, p. 1071) explains that to achieve psychological well-being, individuals should have positive psychological functioning. Individual components that have positive psychological functions include:

a) Self-acceptance. This dimension is the main characteristic of mental health as well as the main characteristics in self-actualization, optimal functioning, and maturity. Good self-acceptance is characterized by 


\section{International Journal of Science and Research (IJSR) \\ ISSN (Online): 2319-7064 \\ Index Copernicus Value (2013): 6.14 | Impact Factor (2014): 5.611}

the ability to accept one's-self as it is. These capabilities allow one to be positive about one's-self and life.

b) Positive relations with others. This dimension has repeatedly been emphasized as an important dimension in the PWB concept. Ryff stressed the importance of establishing a trusted and warm relationship with others. These dimensions also emphasize the ability, which is one of the components of mental health, that is the ability to love others.

c) Autonomy. Autonomy is pertaining to the independence, the ability to be self-determined, and the ability to regulate behavior.

d) The purpose of life. This dimension concerns an individual's ability to achieve goals in life. Someone who has a sense of directivity may hold the belief that the life of the present and the past both have some significance, the belief that gives life purpose, and has a target to achieve in life; he can then be said to have a good life goal dimension. This dimension can be indicative of mental health because individuals cannot escape from his/her beliefs about the purpose and meaning of life when defining mental health.

e) Personal growth. Personal growth dimension depicts the ability of an individual to develop the potential within one's self. In fact, one of the functions of guidance and counseling is to achieve development. This dimension is required by individuals in order to function optimally psychologically. One of the important things in this dimension is the need to self-actualize one-self, for example by openness to new experience.

f) Environmental mastery. An individual with good psychological well-being has the ability to choose and create an environment that suits his physical condition. In other words, He has the ability to deal with external events. This is what is meant by the ability to manipulate situations to fit his own needs and personal values.

Burke (2012), echoing previous studies, contends that most positive psychology interventions aim to enhance positive affectivity. They include savouring (Bryant \& Veroff, 2004), expressing gratitude (Eammons \& McCullough, 2003; Seligman, 2011), intensely positive experiences (Burton \& King, 2004), random acts of kindness (Lyubomirsky, 2007), the best possible self (King, 2001), mindfulness meditation (Davidson et al., 2003), and physical activity (Thayer, Newman, \& McClain, 1994).

Jolanta Burke (2012) conducted a meta-analysis of positive psychology interventions with over 4000 of participants and found that these interventions were particularly more beneficial to younger people, especially those experiencing higher levels of depression (Sin \& Lyubomirsky, 2009).

\section{Subjective Well-Being}

In an article co-authored by Diener, Suh, Lucas, and Smith (1999), the term SWB has been used to refer to how people evaluate their lives. SWB includes such variables as life satisfaction, lack of depression and anxiety, as well as the mood and positive emotions. One's index of SWB is calculated from a score of two main variables, namely happiness and satisfaction in life.
People whose index of SWB is high are those who are satisfied with their lives, often feel happy and rarely experience unpleasant emotions such as sadness or anger. Conversely, people whose SWB index is low are those who are less satisfied with their lives, rarely happy and more often undergo unpleasant emotions, such as anger or anxiety.

There are three major components of SWB, namely satisfaction, pleasant affectivity, and low level of unpleasant affectivity. General satisfaction can be divided into satisfaction in various areas of life, such as recreation, love, marriage, friendship, and so forth. Pleasant affectivity can be divided into specific emotions, such as happiness, affectivity, and self-esteem. Unpleasant affectivity can be divided into specific emotions and mood, such as shyness, anger, sadness, guilt, and anxiety (Diener, et. al., 1999).

Thus, PWB developed by Ryff et. al. are eudemonic, in that someone is said to experience well-being when his life is filled with things that are meaningful, purposeful, useful for the well-being of others and for his own growth (Ryff and Singer, 2008). As for the SWB, it is hedonic in nature which contains the principles of enjoyment, namely the extent to which a person feels his life enjoyable, stress-free, and free from anxiety, depression and the like.

\section{Islamic Religiosity}

Glock and Stark (cited in El-Menouar, 1996) contend that religiosity is the attitude resulted from internalization of religion into oneself. Furthermore, religiosity serves as a system of symbols, a system of belief, a system of value, and a system of behaviors centered on the problems experienced as the most meaningful. A religious person will try to always be obedient to the teachings of his religion, trying to learn the religious knowledge, trying to perform his religious rituals, believing in his religion's doctrines and feeling the religious experience. Dradjat (1995) divided religiosity into awareness to embrace a religion and the religious experience (experience to have a religion).

\section{Previous Studies}

Keyes, Shmotkin, and Ryff (2002), using factor analysis, found that SWB and PWB are conceptually related, but are empirically different. The sample of this research consisted of 3,032 people aged between 25 to 74 years. Similarly, Linley et. al. (2009), examined the underlying factors of SWB in the UK using exploratory and confirmatory factor analyses. It was found that factor loading resulted in two independent factors, but these two factors are interrelated. In both studies, SWB and PWB are found to be two distinct, but related, constructs.

As for the relationship between religiosity and well-being, there is a study reporting that there is no correlation between religiosity and well-being (e.g. Walker, 2009). The author, in his dissertation, distinguishes between spirituality and religiosity. Three different scales were employed in his study referred to as Spiritual Involvement and Beliefs Scale, the Scales of Psychological Well-Being, and the Satisfaction with Life Scale. Data were analyzed using multiple regressions, correlation, and independent samples t-tests. The results show that spirituality is a positive predictor of 


\section{International Journal of Science and Research (IJSR) \\ ISSN (Online): 2319-7064}

Index Copernicus Value (2013): 6.14 | Impact Factor (2014): 5.611

the SWB and PWB. As for religiosity, it was found to be significantly associated with neither SWB nor PWB. View

However, Aflakseir (2012) conducted a study with 60 Muslim students at the University of Southampton and Birmingham in the UK and found that Muslim students look at life meaningfully and the significant source of the meaning of life comes from their religious activities and a good relationship with the family. Only a few reported to come from hedonistic activities and ownership of objects. The study also found a positive relationship between the meaning of life with the components of PWB, spirituality, and religiosity. Likewise, a study by Tiliouine et. al. (2009) involving 2909 respondents in Algeria, suggests that religiosity is positively and strongly associated with SWB.

However, neither Tiliouine at. al. (2009) nor Alfaksier (2012) addressed the question pertaining to the strength of the relationship and the effect of Islamic religiosity on each construct of well-being - SWB and PWB. The study reported here seeks to fill this gap in research.

\section{Theoretical Relationship of Research Variables}

One dimension of PWB pertains to the purpose of life. This dimension concerns the individual's ability to achieve goals in life. Someone who has a sense of directivity in life has the feeling that the life of the present and the past has some significance, holding the belief that gives life purpose, and has a target to achieve in life; he can then be said to have a dimension of good life goals. This dimension is closely associated with transcendence where all the problems of life are subject to God. Individuals who have high levels of religiosity are more able to make positive sense of the events of his life in such a way that life becomes more meaningful.

These positive feelings and life satisfaction as the core of the SWB can derive from religiosity. Religious experience and religious practices constitute the core of SWB. This suggests that well-being is closely related to religiosity. In fact, the work of Krause (2003) suggests that purport to God is an important source for a person's PWB. In this study, PWB is measured by a person's life satisfaction, self-esteem, and optimism. This measurement of PWB is akin to SWB. Similarly, research by Maltby, Lewis and Day (1999) found a significant correlation between religiosity and PWB. Frequency of personal prayer is a dominant factor in the relationship between religiosity and PWB.

To follow from the above, it is clear that SWB, PWB, and religiosity are related to each other as shown below.

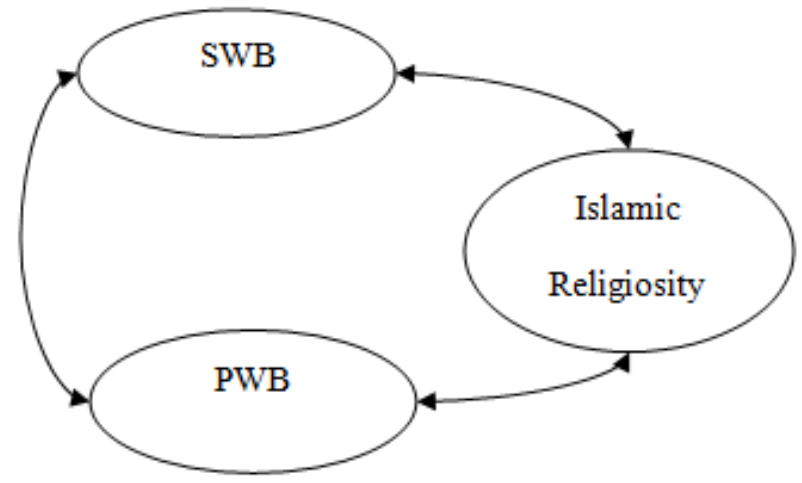

Figure 1: Relationship of research variables

\section{Research Methods}

Respondents of this study were IAIN students Kendari, taken by accidental sampling technique. In total there were 159 respondents to this study. The age of respondents ranged from 18 to 22 years old and they were on the $2^{\text {nd }}$ and $4^{\text {th }}$ semester.

\section{Research Design}

This study is non-experimental quantitative research. Data collection on research variables was conducted using questionnaires administered to each respondent.

\section{Instrumentation}

Three major questionnaires were employed during data collection process: SWB questionnaire, PWB questionnaire, and Religiosity the details of which will be discussed below.

\section{1) SWB Questionnaire}

SWB questionnaire in this study consisted of measuring life satisfaction, positive and negative feelings. These items are adapted from the Satisfaction with Life Scale (SWL) and the Scale of Positive and Negative Experience developed by Ed Diener and Robert Biswas-Diener (2009). Respondents rate themselves against 5 items of SWL, ranging from 1 (strongly disagree) to 7 (strongly agree). Sample item for SWL scale includes "I am satisfied with my life now". A single adjective (e.g. happy, sad) was used to measure positive and negative affectivity of the respondents. Respondents were asked to measure how often they experienced the situation (i.e. feeling happy, sad, etc.) during the last 3 weeks by putting a thick $(\checkmark)$ below 5 (very often) up to 1 (never). Validity and reliability of SWB questionnaire can be seen in the following table.

Table 1: Validity and Reliability of SWB Questionnaire

\begin{tabular}{|l|l|l|l|l|}
\hline Component & $\sum$ items & Coef. $\alpha$ & $\begin{array}{l}\sum_{\text {items }} \text { valid } \\
\text { Loef. } \alpha\end{array}$ \\
\hline Life Satisfation & 5 & 0,666 & 4 & 0,760 \\
\hline Positive Affectivity & 9 & 0,805 & 9 & 0,805 \\
\hline Negative Affectivity & 9 & 0,649 & 9 & 0,649 \\
\hline
\end{tabular}

Note that the reliability of each dimension of the questionnaire is relatively high. For the dimension of life satisfaction, $\alpha=0.76$, positive affectivity $\alpha=0.805$, and negative affectivity $\alpha=0.64$. Invalid items were removed. Factor analysis was then performed with valid items to examine the contributions of these items to the SWB. Based on the results of factor analysis, 9 items were obtained for the measurement of positive affectivity and 9 items for the 


\section{International Journal of Science and Research (IJSR) \\ ISSN (Online): 2319-7064}

Index Copernicus Value (2013): 6.14 | Impact Factor (2014): 5.611

measurement of negative affectivity. Thus, the total number of items used in the measurement of positive and negative affectivity was 18 , and 4 items for the measurement of life satisfaction.

\section{PWB Questionnaire}

PWB questionnaire in this study was adapted from Ryff's Scales of PWB developed by Ryff. Ryff's Scales of PWB comprised 84 statements and there is also a version consisting of 54 questions. However, for the purpose of this study, only 24 statements were employed. These 24 statements consisted of 6 dimensions namely autonomy, environmental mastery, personal growth, positive relations with others, purpose in life and self-acceptance. Sample item includes "Maintaining a close relationship is hard for me and it even makes me frustrated."

Respondents were asked to respond to each statement by putting a thick $(\checkmark)$ under 1 (strongly disagree) up to 6 (strongly agree). Responses were calculated for each dimension. Half of the items were negatively/ unfavorably worded and need to be reverse coded in the analysis. For each category, higher scores indicate respondents' comfort whereas low scores indicate respondents' discomfort in the respective dimension. Results of validity and reliability of PWB questionnaire can be seen in table 2 below.

Table 2: Validity and Reliability of PWB Questionnaire

\begin{tabular}{|c|c|c|c|c|}
\hline Component & $\sum_{\text {items }}$ & Coef. $\alpha$ & $\begin{array}{c}\text { ivalid } \\
\text { item }\end{array}$ & Koef. $\alpha$ \\
\hline Autonomy & 4 & 0,336 & 2 & 0,367 \\
\hline Environmental Mastery & 4 & 0,537 & 3 & 0,537 \\
\hline Personal Growth & 4 & 0,216 & 1 & 0,283 \\
\hline $\begin{array}{c}\text { Positive Relations with } \\
\text { Others }\end{array}$ & 4 & 0,391 & 3 & 0,517 \\
\hline Life Goals/ Purpose in Life & 4 & 0,22 & 2 & 0,459 \\
\hline Self-Acceptance & 4 & 0,315 & 2 & 0,433 \\
\hline
\end{tabular}

Note that reliability of each dimension of the PWB questionnaire is not that high, ranging from 0.283 to 0.537 , although its overall reliability equals 0.76 , which is relatively high. A factor analysis was subsequently performed to examine the contributions of these items to PWB. The results of the analysis yielded two items (item \#1 and \#19) labeled as the dimensions of autonomy, 3 items (item \#8, item \#14, and item \#20) labeled as the dimensions of environmental mastery, one item (item \#15) labeled as the dimension of personal growth, 3 items (item \#4, item \#16, item \#22) labeled as the dimensions of positive relationships with others, 2 item (item \#11 and item \#23) labeled as the dimensions of the purpose of life and 2 items ( item \#12 and item \#24) labeled as the dimensions of self-acceptance. Thus, the PWB questionnaire employed in this study comprised a total of 13 items.

\section{Religiosity Questionnaire}

Religiosity questionnaires were developed based on the dimensions of religiosity of Hisham Abu Raiya (2008) and Glok and Stark (cited in El-Menouar, 2014). The questionnaires were of a Likert-Scale format containing closed questions in the form of favorable and unfavorable statements. Aspects of religiosity was subsequently developed into 33 items of religiosity using multiple answers.
Table 3: Validity and Reliability of Religiosity Questionnaire

\begin{tabular}{|l|l|l|}
\hline \multicolumn{1}{|c|}{ Component } & $\sum$ valid items & \multicolumn{1}{c|}{ Coef. $\alpha$} \\
\hline Ideological Aspect & $2(2,4)$ & 0,669 \\
\hline Ritual Aspect & $3(6,7,8)$ & 0,599 \\
\hline Islamic Positive Religious Coping & $7(9$ to 15$)$ & 0,775 \\
\hline Islamic Negative Religious Coping & $2(7,18)$ & 0,440 \\
\hline Consequential Aspect & $4(21$ to 24$)$ & 0,616 \\
\hline Spiritual Aspect & $9(25$ to 33$)$ & 0,822 \\
\hline
\end{tabular}

Overall reliability of the questionnaire (33 items) is $\alpha=$ 0.835 . After deleting invalid items, however, the $\alpha$ went up to 0,859 (26 items). Reliability of each component is relatively good ranging from 0,44 to 0,822 . Following the reliability analysis, 27 valid items were obtained and subsequent factor analysis resulted in a total of 24 items.

\section{Results}

Table 4 below shows that SWB and PWB are two distinct dimensions independent of each other. Thus, it can be concluded that SWB and PWB are two different psychological constructs.

Table 4: Rotated Component Matrix ${ }^{\mathrm{a}}$

\begin{tabular}{|c|c|c|}
\hline & \multicolumn{2}{|c|}{ Component } \\
\hline & 1 & 2 \\
\hline PWB & .938 & .194 \\
\hline Life Satisfaction & -.018 & .824 \\
\hline Negative Affectivity & -.616 & .051 \\
\hline Positive Affectivity & .364 & .664 \\
\hline SWB & -.192 & .934 \\
\hline PWBAutonomy & .411 & -.229 \\
\hline PWBEnv.Mastery & .686 & .361 \\
\hline PWB Pers. Growth & .685 & -.030 \\
\hline PWB Relation & .644 & -.010 \\
\hline PWB Purpose & .605 & .114 \\
\hline PWB Self-Accept & .432 & .344 \\
\hline \multicolumn{3}{|c|}{$\begin{array}{l}\text { Catatan:Extraction Method: Principal Component Analysis. } \\
\text { Rotation Method: Varimax with Kaiser Normalization. }\end{array}$} \\
\hline
\end{tabular}

This study shows that the SWB and PWB are two different constructs. In fact, this study suggests that these two constructs are completely unrelated. To put it more bluntly, a person can experience happiness and be satisfied with his/her life and experience positive affectivity, but the person does not necessarily undergo personal growth, have positive relationship with others, have autonomy in his daily life, or accept his/her own weaknesses and strengths.

The results of Pearson Product Moment correlation showed that there is no significant correlation between SWB and PWB (Table 5 below). This, in turn, suggests that a person with higher SWB does not necessarily have higher PWB and the reverse is also true. So, a person feeling happy and satisfied does not necessarily mean that he will experience personal growth or have a positive relationship with others. 


\section{International Journal of Science and Research (IJSR) \\ ISSN (Online): 2319-7064}

Index Copernicus Value (2013): 6.14 | Impact Factor (2014): 5.611

Table 5: Table Correlations

\begin{tabular}{|c|c|c|c|c|}
\hline & & PWB & Religiosity & SWB \\
\hline \multirow[t]{3}{*}{ PWB } & Pearson Correlation & 1 & $.362^{* *}$ & 0.037 \\
\hline & Sig. (2-tailed) & & 0.001 & 0.646 \\
\hline & $\mathrm{N}$ & 159 & 159 & 159 \\
\hline \multirow[t]{3}{*}{ Religiosity } & Pearson Correlation & $.362^{* *}$ & 1 & 0.084 \\
\hline & Sig. (2-tailed) & 0.001 & & 0.299 \\
\hline & $\mathrm{N}$ & 153 & 155 & 154 \\
\hline \multirow[t]{3}{*}{ SWB } & Pearson Correlation & 0.037 & 0.084 & 1 \\
\hline & Sig. (2-tailed) & 0.646 & 0.299 & \\
\hline & $\mathrm{N}$ & 159 & 159 & 159 \\
\hline
\end{tabular}

As seen from the above table, the Pearson Product Moment correlation showed insignificant relationship between religiosity and SWB. This does not, however, imply that a person with higher religiosity will never experience despair, anger, or anxiety in his live.

Finally, test results with Pearson Product Moment correlation indicate that there is a significant correlation between religiosity and PWB. This suggests that a person with higher religiosity is inclined to experience higher PWB and the reverse is also true.

\section{Discussion}

This study shows that PWB and SWB are two different constructs and they are not even related. Note that the results of this study differs slightly from those of Keyes, Shmotkin and Ryff (2002) reporting that whereas the two constructs are distinctive, they are related. This study further confirms the claim that hedonic happiness (SWB) is, indeed, different from eudemonic happiness (PWB).

This study also shows that the smallest contribution of each dimension of PWB is contributed to by the dimensions of autonomy. It is perhaps not too surprising since the study was conducted with respondents who have come from collectivistic cultural background. Triandis (2002) points out that people from collectivistic cultures tend to define themselves as part of a group and give priority to the objectives of the group. Collectivistic cultural background showed a high need for affiliation and people will thus put the needs of the group above personal needs. On the other hand, autonomy would seem to thrive in individuals who grow in individualistic, rather than collectivistic, cultures.

The study also shows that religiosity is closely related to PWB, which is eudemonic in nature. This is understandable since religiosity is associated with the transcendence of all the problems of life to the Lord. Individuals who have high levels of religiosity are better able to interpret the events of their life in a positive way so that life becomes more meaningful. It is this meaning of life that makes a person feel and experience PWB, that is, to undergo personal growth, to be able to master challenges and obstacles in his environment because of the close feelings to the transcendence.

\section{Concluding Remarks}

This study does not involve such variables as age, educational background, occupation, gender and gender orientation, which could potentially serve as important variables in relation to happiness and PWB. These variables could be an intermediate or moderating variable in the variation of one's happiness. Further research should, therefore, consider these variables. Additionally, SEM (Structural Equation Model) is recommended for the analysis so that further relationship between variables can be tested regarding the position of the variable, be it moderating, endogen, or exogen variables. In particular, it is important to examine further whether religiosity is an antecedent variable for PWB or whether PWB is the exogen variable.

\section{References}

[1] Aflakseir, A. (2012). Religiosity, Personal Meaning, and Psychological Well-being: A Study among Muslim Students in England. Pakistan Journal of Social and Clinical Psychology. Vol. 9, No. 2, 27-31

[2] Burke, J. (2012). Positive Psychology In Guidance And Counselling. National Centre for Guidance in Education (NCGE).

[3] Daradjat, Z., (1995). Ilmu Jiwa Agama. Jakarta : Bulan Bintang

[4] Diener, Ed.,Suh, Eunkook M.,Lucas, R.E dan Smith, H.L. (1999). SWB: Three decade of progress. Psychological Bulletin. Vol.125. No.2. 276-302

[5] El-Menouar, Y.,(2014). The five dimensions of muslim religiosity. Methods, Data, Analyses. Vol. 8(1), 53-78. DOI: $10.12758 / \mathrm{mda} .2014 .003$

[6] Higher education commision (2012), Introduction to Guidance and Counseling, Columbia University.

[7] Kathryn, B., Kathie C., Elmarie, K., \& Mira, P. (2013). A Window on School Guidance Counselling, New zealand. Journal of counseling.

[8] Keyes, K.L, Shmotkin, D \& Ryff, C.D. (2002). Optimizing Well-Being: The Empirical Encounter of Two Traditions. Journal of Personality and Social Psychology. Vol. 82, No. 6, 1007-1022

[9] Krause, N., (2003). Religious meaning and subjective well being in late life. Journal of Gerontology: SOCIAL SCIENCE, Vol. 58B, No.3, S160-S170

[10] Linley, P.A. Maltby, J., Wood, A.M., Osborne, G. \& Hurling, R. (2009).Measuring happiness: The higher order factor structure of subjective and psychological well-being measures. Personality and Individual Differences 47 878-884

[11] Mailani, Q., (2013). Hubungan antara religiusitas dengan resiliensi pada wanita muslimah bercadar dewasa awal di Kota Bandung. Skripsi, Universitas Pendidikan Indonesia, Repository.upi.edu

[12] Maltby, J.,Lewis, C.A., \& Day, L. (1999). Religious orientation and psychological well being: The role of the frequency of personal prayer. British Journal of Health Psychological. Vol. 4, 363-378

[13] Maulina, S.I.,(2010). Hubungan religiusitas dengan psychological well being pada lansia, Jakarta: Universitas Gunadarma 


\section{International Journal of Science and Research (IJSR) \\ ISSN (Online): 2319-7064}

Index Copernicus Value (2013): 6.14 | Impact Factor (2014): 5.611

[14]Piedmont,R.L., Map, A.T., \& Williams, J.E.G.(2007) A factor analysis of the Fetzer/NIA brief multidimensional measure of religiousness/spiritually (MMRS) Research in The Social Scientific Study Religion, Vol.17, hal 177198

[15]Robertson, P.J. (2013), The well-being outcomes of career guidance, British Journal of Guidance \& Counselling, 41:3, 254-266, DOI: 10.1080/03069885.2013.773959

[16] Rinasti, F. (2010) Hubungan antara Tingkat Religiusitas dengan $S W B(S W B)$ pada Remaja Awal Universitas Gunadarma

[17] Ryff, C.D. (1989). Happiness is everything, or is it? Explorations on the meaning of psychological wellbeing. Journal of Personality and Social Psychology. Vol.57. No.6, 1069-1081

[18] Ryff, C.D. \& Singer, B.H. (1996). Psychological Well Being: Meaning, Measurement and Implications for Psychotherpy Research. Psychoteraphy and Psychosomatic. Vol.65, 14-23

[19] Ryff, C.D. \& Singer, B.H.(2008). Know thyself and become what you are: A eudaimonic approach to psychological well-being. Journal Of Happines Studies. 9:13-39. DOI 10.1007/s10902-006-9019-0

[20] Tiliouine, H, Cummins, R.A. \& Davern, (2009) Islamic religiosity, SWB, and health. Mental Health, Religion \& Culture , Vol. 12, No. 1, January 2009, 5574

[21] Triandis, H.C., (2001). Individualism-collectivism and personality. Journal of Personality, 69, 907-924

[22] Wahyuningsih, H. (2009). Validitas konstruk alat ukur Spirituality Orientation Inventory (SOI), Jurnal Psikologi, Vol 36, No.2, 116-129

[23] Walker, M.E. (2009). Relationship of spirituality, SWB, and psychological well-being in a population of African-American college students. Disertasi, ProQuest Dissertations and Theses, 